\title{
Production of volatile fatty acids from slaughterhouse blood by mixed-culture fermentation
}

\author{
Jersson Plácido ${ }^{1,2}$ (1) Y Yue Zhang ${ }^{1}$ \\ Received: 22 January 2018 / Revised: 4 April 2018 / Accepted: 6 April 2018 / Published online: 5 May 2018 \\ (C) The Author(s) 2018
}

\begin{abstract}
The volatile fatty acid (VFA) production potential from animal blood and the factors affecting this process were investigated in this study. In order to simulate an industrial process different operation modes, batch, fed batch and semi-continuous, were also evaluated. Due to high ammonia concentration in fermentation broth, VFA concentration up to $100 \mathrm{~g} \mathrm{~L}^{-1}$ was achieved without addition of buffer and methanogen inhibitor. In general, acetic, $n$-butyric and iso-valeric acids were the most predominant species, although different operational conditions affected the VFA concentration, profile, production rate and yield. The microbial community analysis was conducted on the reactors with the best performance, revealing that 70-90\% of the microbial population was from the Clostridiales order with a strong presence from the Sporanaerobacter genus. These results demonstrated the feasibility of a VFA platform bio-refinery using high-protein wastes as substrate via mixed-culture fermentation under non-sterilised conditions.
\end{abstract}

Keywords Mixed-culture fermentation · Volatile fatty acids · Slaughterhouse blood $\cdot$ Enzymatic hydrolysis, bio-refinery

\section{Introduction}

The European Union produces more than 40 million tonnes of meat every year [1], with pig meat being the most important source $(51 \%)$ followed by poultry $(30 \%)$, bovine $(17 \%)$ and sheep and goat meat (2\%) [1]. Meat production is associated with the generation of different types of solid (intestines, fat, bowels, etc.) and liquid (blood, manure, washing water, etc.) wastes [2]. Livestock blood from slaughterhouses is a proteinrich waste. As most protein-rich waste stream, its organic fraction is principally composed of proteins (94.4\%), lipids $(0.3 \%)$ and carbohydrates (5.3\%) [3]. In order to transform blood into biogas via anaerobic digestion without suffering

Electronic supplementary material The online version of this article (https://doi.org/10.1007/s13399-018-0313-y) contains supplementary material, which is available to authorized users.

Jersson Plácido

j.e.placidoescobar@swansea.ac.uk

1 Water and Environmental Engineering Group, Faculty of Engineering and the Environment, University of Southampton, Southampton, UK

2 Centre for Cytochrome P450 Biodiversity, Institute of Life Science, Medical School, Swansea University, Swansea SA2 8PP, Wales, UK from ammonia toxicity, different strategies have been tested including inoculum acclimation, dilution and/or co-digestion [3-5]. VFA, however, could still be accumulated significantly even with those measures in place. For instance, Zhang and Banks [4] reported that the VFA reached up to $15 \mathrm{~g} \mathrm{~L}^{-1}$ when digesters were fed with organic fraction of municipal solid waste and sheep blood at a ratio of 80:20 on a volatile solid basis. The production of considerable quantities of VFA induced by blood addition to digesters has only been regarded as detrimental to the process previously: it is often difficult to reduce these VFA accumulations and re-start methanogenesis. This observation, however, can be applied for production of VFA as renewable bulk chemicals.

Other investigations have proved that it is possible to produce organic acids using anaerobic processes by inhibiting the methane production and acid consumption [6-9]. However, all these substrates were carbohydrate-based residues such as paper wastes, lignocellulosic material, municipal solid wastes, etc. Protein-rich residues such as slaughterhouse blood have not been evaluated as substrates in the production of VFA yet, although this waste stream has several advantages for VFA production: the ammonia produced from acidogenesis can inhibit methanogenesis, provide buffering capacity to fermentation process and supply nutrients to microbial biomass. Therefore, in principle, there is no external methanogen inhibitor, buffer and nutrients required when using protein-rich 
materials as substrate; thus, the operating cost is minimised at this aspect.

The aim of this study was to prove that significant VFA production can be achieved under non-sterilised mixed-culture conditions using slaughterhouse blood as substrate. The experimental methodology was initially looked at the batch kinetics of acid production from blood under conditions in which methanogenic activity is inhibited, to determine rates of production and the ratio of different acid products. This provided a first indication of process feasibility. As syntrophy and other complex interactions in the systems biology exert a strong influence on product formation and speciation, much of the research effort was thus spent on determining yields and productivities in semi-continuous trials to assess the effects of process manipulations in the systems biology, with the aim of maximising the accumulation of recoverable intermediate acid products.

\section{Materials and methods}

\subsection{Materials}

\subsubsection{Substrate}

The blood solution used in this study was prepared by mixing one part of dried blood (Tongmaster Seasonings, Lanarkshire, UK) with six parts of deionised water. This solution had a total solid (TS) content of $14.3 \%$ and volatile solid (VS) content of $13.5 \%$ on a fresh matter basis, lower than the real slaughterhouse blood which usually has a TS of 18 20\% [3, 4, 10]. This lowered concentration was applied in this study to improve the rheology of reactor mixing in orbital incubator.

\subsubsection{Inoculum}

There were two types of inoculum used in this study: one unacclimated and one acclimated inoculum. The un-acclimated inoculum was collected from an anaerobic digester treating bio-solids (Millbrook Wastewater Treatment Works, Southampton, UK). It was kept at room temperature and sieved through a $1-\mathrm{mm}$ mesh before inoculation to remove large particles. The acclimated inoculum was taken from the semi-continuous fermenter SC1 (section 2.2.3), after it had been running for three hydraulic retention times (HRT) (21 days).

\subsubsection{Enzymatic pre-treatment}

In order to examine if enzymatic pre-treatment could improve VFA production, a $25 \mathrm{~g} \mathrm{~L}^{-1}$ trypsin solution from porcine pancreas (Sigma-Aldrich) was selected to hydrolyse blood proteins. The hydrolysis process was carried out at an initial enzyme load of $1 \%(v / v)[11]$ to the blood solution for $48 \mathrm{~h}$ at $20{ }^{\circ} \mathrm{C}$. Constant mixing at $150 \mathrm{rpm}$ was applied during the hydrolysis.

\subsection{Fermentation experiments}

All experiments listed below were conducted in borosilicate glass reactors. Each of them had a working volume of $1 \mathrm{~L}$, and was sealed with a rubber bung through which a stainless-steel metal tube was inserted and connected to the gas collection bags. To maintain anaerobic conditions, the headspace of the reactors was purged with nitrogen gas when starting the experiments, and when reactors were opened for sampling or for adding iodoform solution. The reactors were kept in an orbital incubator at $37^{\circ} \mathrm{C}$ and $150 \mathrm{rpm}$ during the course of the experiment.

\subsubsection{Batch experiments}

As shown in Table 1, three operational variables were tested for 41 days using four reactors (B1-B4): inoculum acclimation (IA), methanogen inhibitor (MI), and enzymatic hydrolysis $(\mathrm{EH})$. The initial volumetric inoculum and blood loading (BL) of this experiment was 10 and $90 \%$, respectively, by filling $100 \mathrm{~mL}$ of inoculum and $900 \mathrm{~mL}$ of blood solution into each of the reactors. This resulted in a blood loading of $122 \mathrm{~g}$ $\mathrm{VS} \mathrm{L}^{-1}$ at the beginning of the experiment.

\subsubsection{Fed-batch experiment}

This experiment tested the effect of enzymatic hydrolysis on VFA production in fed-batch mode using two reactors: FB1: No-EH and FB2: EH (Table 1). Un-acclimated inoculum was used for this experiment, and no methanogen inhibitor was added during the course of the test. The initial reactor working volume was $450 \mathrm{~mL}$ including $45 \mathrm{~mL}$ of inoculum and $405 \mathrm{~mL}$ of blood solution (FB1) and hydrolysed blood solution (FB2), indicating an initial blood load of $122 \mathrm{~g} \mathrm{VS} \mathrm{L}^{-1}$. The experiment was run in batch mode for the first 7 days, and then the fed-batch operation was initiated. In fed-batch mode, $50 \mathrm{~mL}$ of blood or freshly hydrolysed blood were added to the reactors every 2.3 days without removing fermentation broth. The fed-batch mode was maintained until day 30 when the reactors reached their maximum volume of $1 \mathrm{~L}$, and then the fermentation was continued in batch mode again until day 45 .

\subsubsection{Semi-continuous experiment}

This experiment assessed the effect of initial inoculum loading and enzymatic hydrolysis on VFA production in semicontinuous process with a hydraulic retention time (HRT) of 7 days. As fed-batch experiment, un-acclimated inoculum was used for this experiment, and no methanogen inhibitor was added during the course of the test. The test was run for nine 
Table 1 Factors evaluated in batch, fed-batch and semicontinuous experiments

$\begin{array}{llll}\text { 1-1 reactor experiment in batch } \text { mode }^{1} & & \\ \text { Reactor } & \text { Factors evaluated } & & \\ & \text { Inoculum acclimation } & \text { Enzymatic hydrolysis } & \text { Methanogen inhibitor } \\ \text { B1 } & \text { No } & \text { No } & \text { No } \\ \text { B2 } & \text { No } & \text { No } & \text { Yes } \\ \text { B3 } & \text { Yes } & \text { No } & \text { No } \\ \text { B4 } & \text { Yes } & \text { Yes } & \text { No }\end{array}$

Fed-batch experiment ${ }^{1,2}$

Reactor Factors evaluated

Enzymatic hydrolysis

FB1

No

FB2

Yes

Semi-continuous experiment ${ }^{2,3}$

Reactor

Factors evaluated

Inoculum loading

$10 \%$

$\mathrm{SC} 1$

$67 \%$

$10 \%$

$67 \%$
Enzymatic hydrolysis

No

No

Yes

Yes

${ }^{1}$ The initial blood load was $122 \mathrm{~g} \mathrm{VS} \mathrm{L}^{-1}$ for batch and fed-batch experiments

${ }^{2}$ The fed-batch and semi-continuous experiments did not have methanogen inhibitor

${ }^{3}$ The initial blood load was $122 \mathrm{~g} \mathrm{VS} \mathrm{L}^{-1}$ for reactor SC1 and SC3 when it was run in batch mode for the first 7 days, and then, their organic loading rate was $19 \mathrm{~g} \mathrm{VS} \mathrm{L}^{-1}$ day $^{-1}$ in semi-continuous mode. Reactors SC2 and $\mathrm{SC} 4$ were run in semi-continuous mode from day 1 and their organic loading rate was $19 \mathrm{~g} \mathrm{VS} \mathrm{L}^{-1}$ day $^{-1}$ as well

HRT (63 days) using four reactors, SC1-SC4. As shown in Table 1, two initial blood loading levels were tested: 90 and $33 \%(v / v)$, and each were used to ferment both untreated blood and freshly hydrolysed blood solutions. In this experiment, different start-up procedures were adopted for different initial blood loading. The reactors (SC2 and $\mathrm{SC} 4$ ) with initial blood loading of $33 \%$ were operated in semi-continuous mode from the beginning: $670 \mathrm{~mL}$ inoculum and $330 \mathrm{~mL}$ of blood solution ( $135 \mathrm{~g}$ blood $\mathrm{VS} \mathrm{L}^{-1}$ ) were filled in the reactors on day 0 . Then, after every 2.3 days, $330 \mathrm{~mL}$ of fermentation broth was replaced with $330 \mathrm{~mL}$ of blood solution, corresponding to an average organic loading rate of $19 \mathrm{~g} \mathrm{VS} \mathrm{L}^{-1}$ day $^{-1}$. The reactors (SC1 and SC3) with initial blood loading of $90 \%$ were started in batch mode during the first HRT (7 days) to avoid the wash-out effect: $100 \mathrm{~mL}$ inoculum and $900 \mathrm{~mL}$ of blood solution were filled in the reactors on day 0 , and then after 7 days, the reactors were started semi-continuous operation as described above.

\subsection{Analytical methods}

\subsubsection{VFA concentration}

Samples were centrifuged at $14,000 \mathrm{~g}$ (micro-centrifuge, various manufacturers) for $20 \mathrm{~min}$ and then the supernatant was used for analysis. Where dilution was necessary, deionised water was used. Formic acid was then added to give a concentration of $10 \%$ of the total volume for analysis. The acidified solution was transferred into vials and loaded onto the GC auto-sampler. VFA quantification was performed by a Shimadzu GC-2010 gas chromatograph (Shimadzu, Milton Keynes, UK), using a flame ionisation detector and a capillary column type SGE BP-21. The GC oven temperature was programmed to increase from 60 to $210{ }^{\circ} \mathrm{C}$ in 15 min with a final hold time of $5 \mathrm{~min}$.

\subsubsection{Gas volume and composition}

The fermentation gas was collected by gas-impermeable sampling bags during the fermentation process. Its volume was measured using a weight-type water displacement gasometer and expressed as the volume at standard temperature $\left(0{ }^{\circ} \mathrm{C}\right)$ and temperature (1 atm) [12]. Its composition was quantified using a Varian Star 3800 CX gas chromatograph (Varian Ltd., Oxford, UK) with a thermal conductivity detector. The GC was fitted with a Hayesep C column and employed argon as the carrier gas.

\subsubsection{Soluble protein concentration}

Samples were centrifuged at $14,000 g$ (micro-centrifuge, various manufacturers) for $20 \mathrm{~min}$. The supernatant was then 
added to the Bradford reactive (Bio-Rad Protein Assay) and mixed thoroughly. After 5 min, the mixture was read at $595 \mathrm{~nm}$ using a UV-visible spectrophotometer (Cecil 3000 series, Cecil Instruments). The concentration was calculated by comparing against a Bovine serum albumin standard (BioRad).

\subsubsection{Total ammonia nitrogen concentration}

A sample aliquot was distilled using a Büchi K-350 Distillation Unit (Büchi, UK) and aqueous boric acid with mixed indicator as the receiving solution. The distillate was then titrated manually with $0.25 \mathrm{~N} \mathrm{H}_{2} \mathrm{SO}_{4}$ using a digital titration system (Schott Titroline, Gerhardt UK Ltd). Total ammonia nitrogen (TAN) concentration is expressed in units of $g$ $\mathrm{N} \mathrm{L}^{-1}$, which represents the total concentration of free ammonia and ammonium ion in the sample.

\subsubsection{TS and VS content}

Approximately $10 \mathrm{~g}$ of homogenous sample was transferred into a weighed crucible. Samples were weighed to an accuracy of $1 \mathrm{mg}$ (Sartorius LC6215 balance, Sartorius AG, Gottingen Germany) and placed in an oven (LTE Scientific Ltd., Oldham UK / Heraeus Function Line series, UK) for drying overnight at $105 \pm 1{ }^{\circ} \mathrm{C}$. Samples were then weighed and transferred to a muffle furnace (Carbolite Furnace 201, Carbolite, UK) and heated to $550 \pm 10^{\circ} \mathrm{C}$ for $2 \mathrm{~h}$. After this ashing step, samples were weighted to an accuracy of $1 \mathrm{mg}$.

\subsubsection{DNA extraction and sequencing}

Microbial community analysis was carried out for reactors $\mathrm{SC} 3$ and FB2, with the sample from SC3 taken at the end of the seventh HRT and FB2 sample taken at the end of the process. The samples were stored at $-20{ }^{\circ} \mathrm{C}$ before DNA extraction. DNA was extracted from $200 \mathrm{mg}$ of each sample using a freeze-thaw method. Microbial community analyses were performed based on the V4 region of the 16S rRNA gene [13-15]. Amplification was carried out using the primers as shown in Table 2. Illumina barcode oligonucleotides were used to barcode individual amplicons to allow their identification after sequencing. Next-generation sequencing (NGS) of all amplicons was completed using the illumina MiSeq system with MiSeq Reagent Kit v3. The downstream analysis for taxonomic assignment was completed in three main steps:
(1) Reduction of the dataset size with the selection of operational taxonomic units (OTUs), (2) the most abundant sequence in each OTU cluster was selected as the representative sequence for that cluster for downstream analysis; and (3) taxonomy was assigned to each representative sequence by comparing it against the Green Genes 16S database.

\section{Results}

As the preliminary work, blood loading, methanogen inhibition using iodoform and enzymatic hydrolysis using trypsin were evaluated in batch configuration (see supplementary material). A blood loading of 1 or $5 \%(v / v)$ could not inhibit the methanogenic activity and the VFA accumulated at the beginning of the test was consumed by day 7 and 20, respectively. At higher loadings, a continuous accumulation of VFA was observed until it reached a plateau. At loading of 15-50\%, VFA increased until day 7, whereas the VFA accumulation extended to day 13 for loading 75 and $90 \%$. The initial VFA accumulation rate in a reactor without iodoform addition was usually lower than that of its counterpart with iodoform at the same loading, probably due to the simultaneous VFA consumption by methanogens when the ammonia and/or VFA concentration was still low. This is the reason that caused the lower final concentrations when iodoform was not present. The presence of enzymatic hydrolysis did not alter the final concentration of VFA. The initial VFA production rate, however, was improved considerably. The VFA profiles were also different in reactors fed with hydrolysed blood, although the total VFA concentrations were at the same level. In the reactor with EH pre-treatment, acetic and $n$-butyric acids were dominant, whereas $n$-butyric acid out-competed acetic acid in No$\mathrm{EH}$ reactor. A blood loading of $90 \%$ was therefore chosen for the following experiments.

\subsection{Batch fermentation experiment}

The reactors B1 (Fig. 1a) and B2 (Fig. 1b) presented a similar VFA production pattern as the preliminary experiments described in the supplementary material. Using acclimated inoculum, B3 (Fig. 1c) and B4 (Fig. 1d) achieved a VFA concentration close to $100 \mathrm{~g} \mathrm{~L}^{-1}$, indicating the importance of inoculum selection. No difference was detected on the effect of methanogen inhibitor when using acclimated inoculum, because the methanogens had been inhibited and washed out

Table 2 Primers' sequence used in the pyrosequencing analysis

\begin{tabular}{ll}
\hline Nex_16S_515 F & 5'-TCGTCGGCAGCGTCAGATGTGTATAAGAGACAGGTGYCAGCMGCCGCGGTAA-3' \\
Nex_16S_806 R & 5'-GTCTCGTGGGCTCGGAGATGTGTATAAGAGACAGGGACTACNVGGGTWTCTAAT-3' \\
\hline
\end{tabular}

${ }^{1}$ Primer sequences are underlined, with illumina Nextera Transposase adapters attached 

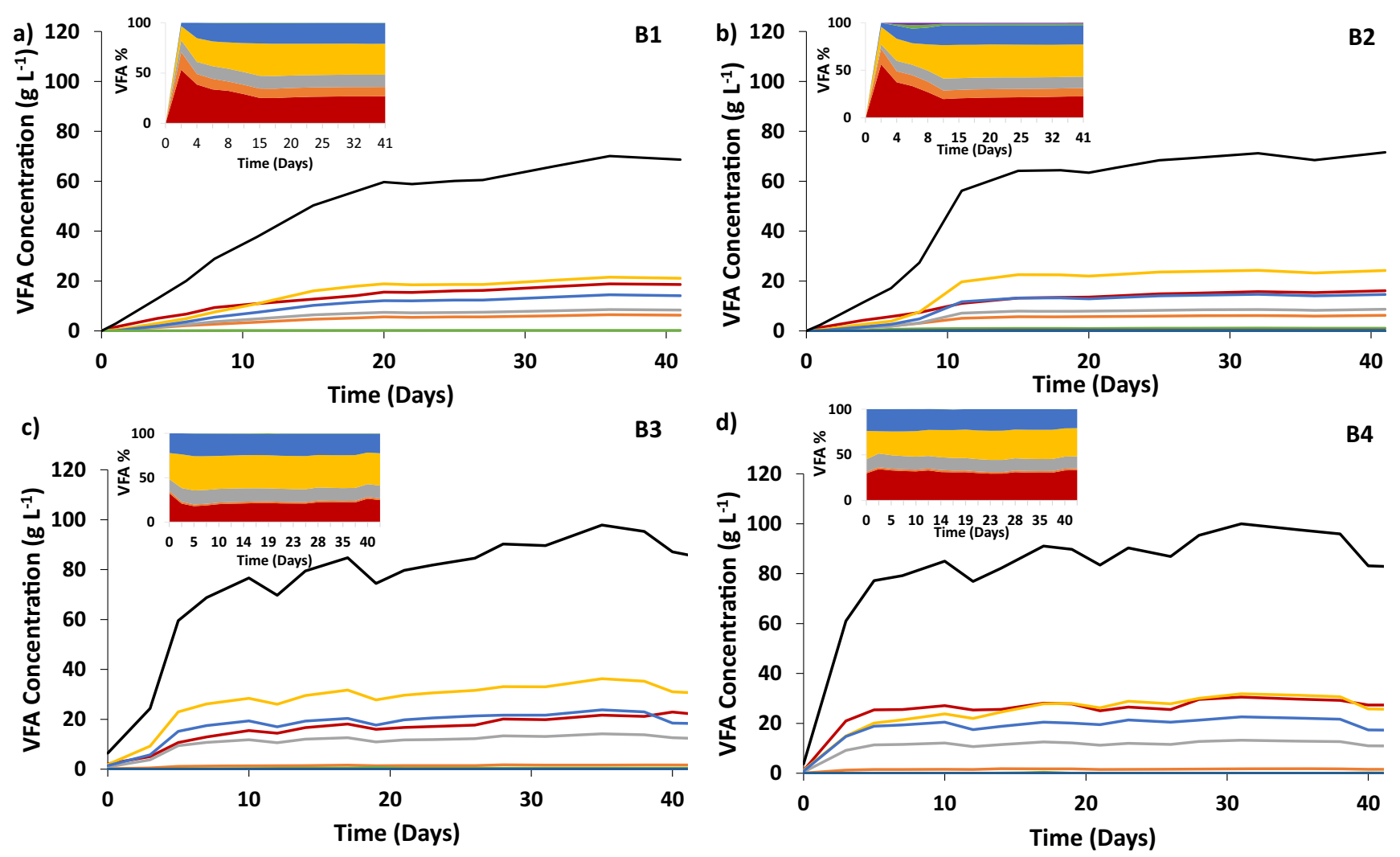

\section{-Acetic - Propionic - Iso-Butyric - n-Butyric - Iso-Valeric - Valeric - Hexanoic -VFA}

Fig. 1 VFA profiles over the course of the 1-L batch experiment. a Reactor B1. b Reactor B2. c Reactor B3. d Reactor B4. The embedded images correspond to the VFA composition for each reactor

before the fermentation broth was taken to inoculate B3 and B4. B4 had the fastest initial VFA production rate and reached $60 \%$ of its final VFA concentrations in 3 days, following by B3 (5 days), B2 (10 days) and B1 (13 day). The high VFA production rate in $\mathrm{B} 3$ and $\mathrm{B} 4$ was attributed by the use of acclimated inoculum (B3 and B4), as well as the enzymatic pre-hydrolysis for B4. In all reactors, $n$-butyric and acetic acids were the most produced acids followed by iso-valeric, iso-butyric, propionic and valeric acids. B3 had the highest concentration of $n$-butyric $\left(35 \mathrm{~g} \mathrm{~L}^{-1}\right)$ and iso-valeric acids $\left(23 \mathrm{~g} \mathrm{~L}^{-1}\right)$ and $\mathrm{B} 4$ achieved the highest concentration of acetic $\left(30 \mathrm{~g} \mathrm{~L}^{-1}\right)$ and iso-butyric acids $\left(13 \mathrm{~g} \mathrm{~L}^{-1}\right)$. The reactors using acclimated inoculum, however, had much less propionic acid concentration $\left(<2 \mathrm{~g} \mathrm{~L}^{-1}\right)$ than that of B1 and B2 $\left(>6 \mathrm{~g} \mathrm{~L}^{-1}\right)$.

In all reactors, the VFA production was linked with protein consumption and TAN production (Fig. 2). As VFA production rate was different in different reactors, protein consumption rate was also different and reflected the VFA production kinetics. TAN production occurred at the same time as the reduction in protein concentration and the increase in VFA concentration, which provided a sufficient buffering capacity for all reactors and maintained their $\mathrm{pH}$ between 6.7 and 8.2 throughout the process. The TAN content reached a level of $5 \sim 7 \mathrm{~g} \mathrm{~N} \mathrm{~L}^{-1}$ towards the end of experiment.

\subsection{Fed-batch experiment}

The effect of enzymatic hydrolysis was also tested in fedbatch experiment, FB1: No-EH and FB2: EH (Fig. 3). Although the EH pre-treatment only affected the initial VFA production rate in batch mode; in fed-batch mode, it also influenced the final VFA concentration. The EH reactor (FB2) achieved a higher concentration $\left(100 \mathrm{~g} \mathrm{~L}^{-1}\right)$ than the No-EH reactor (FB1) $\left(80 \mathrm{~g} \mathrm{~L}^{-1}\right)$. The constant addition of hydrolysed blood generated similar VFA concentrations as the batch reactors using acclimated inoculum $\left(100 \mathrm{~g} \mathrm{~L}^{-1}\right)$ and greater than the batch reactors using un-acclimated inoculum $\left(70 \mathrm{~g} \mathrm{~L}^{-1}\right)$.

The acid profile was different in these two reactors. Acetic acid was the predominant VFA species $(32 \%$ on a mass basis) in FB1, followed by $n$-butyric $(25 \%)$ and isovaleric (20\%) acid. Acetic and $n$-butyric acid had equal $30 \%$ share in FB2 when pre-hydrolysis applied, but the percentage of iso-valeric acid was still in the third place $(21 \%)$. Both reactors had a same iso-butyric acid percentage of $12 \%$. Propionic acid was the fifth dominant species, and accounted for 10 and $6 \%$ in FB1 and FB2, respectively. The VFA profile resulted from pre-hydrolysed blood was the same in both batch and fed-batch fermentation 
Fig. 2 Protein consumption and TAN concentration in 1-L batch experiment. a B1 and B2. b B3 and B4

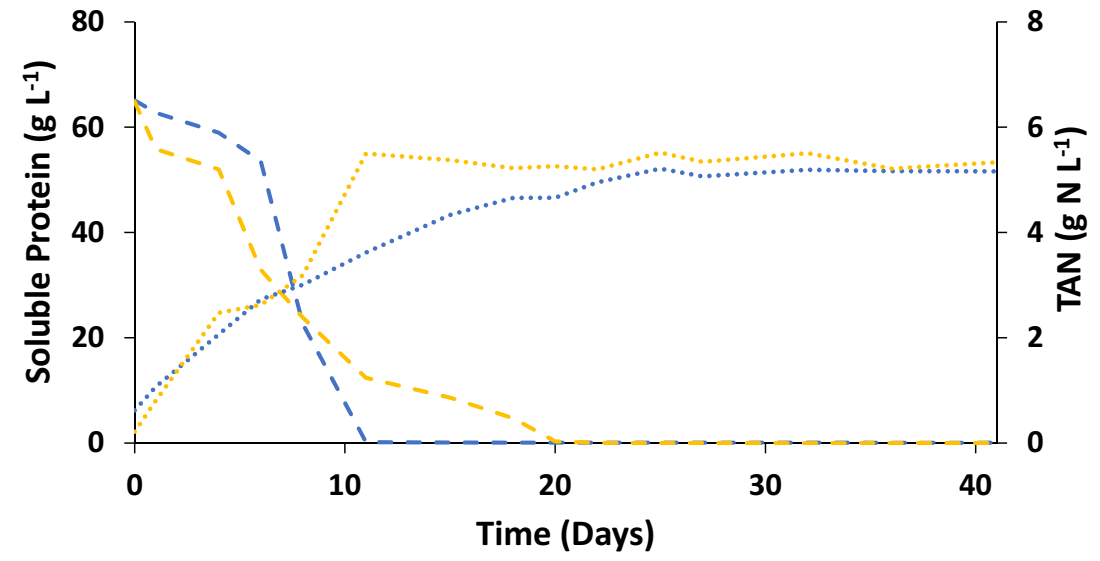

- - Soluble Protein (B1) - - Soluble Protein (B2) ….. TAN (B1) ….. TAN (B2)

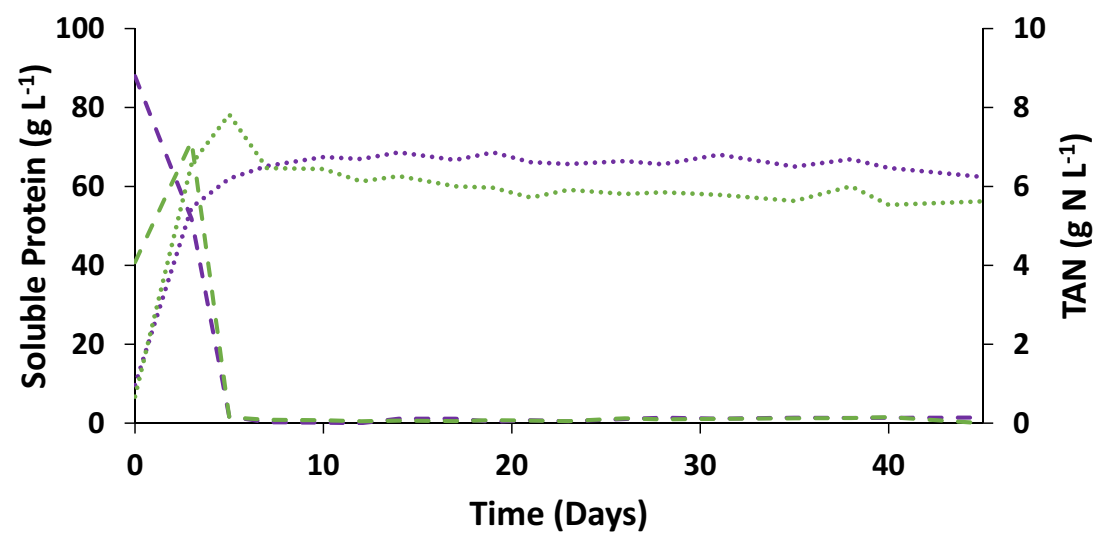

- - Soluble Protein (B3) - - Soluble Protein (B4) ..... TAN (B3) ..... TAN (B4) processes; however, the operation mode seemed to affect the percentage of acetic and $n$-butyric acid when the substrate was not pre-treated.

A same correlation between protein consumption and TAN and VFA production was observed in fed-batch reactors (Fig. 3c), as shown in batch reactors. FB2 consumed proteins faster than FB1 at initial days, and this trend was maintained for the rest of the experiment duration. The $30 \%$ higher TAN concentration in FB2 compared with that of FB1 also reflected upon their different VFA production level. Fed-batch fermentation also maintained a stable $\mathrm{pH}$ (6.9-7.4).

Similar to VFA and TAN production, the fermentation gas production also reflected blood consumption (Fig. 3d). As in batch reactors, the principal gas produced from both fed-batch reactors was $\mathrm{CO}_{2}$, followed by $\mathrm{CH}_{4}$ and $\mathrm{H}_{2}$. FB2 formed a greater amount of gas than FB1, along with its higher VFA production. There was clear $\mathrm{CH}_{4}$ production from $\mathrm{FB} 1$ after feeding stopped, probably because the TAN level in that reactor was not sufficiently high to inhibit methanogens. $\mathrm{H}_{2}$ content was no more than $0.2 \%$ after the start-up stage in both reactors.

\subsection{Semi-continuous experiment}

There were four reactors used for semi-continuous experiment: SC1 BL90\% and No-EH, SC2 BL33\% and No-EH, SC3 BL90\% and $\mathrm{EH}$, and SC4 BL33\% and $\mathrm{EH}$. As shown in Fig. 4, SC1 reactor had the highest concentration of VFA (Fig. 4a) during the initial days of the fermentation $\left(80 \mathrm{~g} \mathrm{~L}^{-1}\right)$, and its VFA production was stable during the first four HRTs. In $\mathrm{SC} 1$, acetic $\left(25 \mathrm{~g} \mathrm{~L}^{-1}\right)$ and $n$-butyric acids $\left(25 \mathrm{~g} \mathrm{~L}^{-1}\right)$ had the highest concentrations, followed by iso-valeric $\left(17 \mathrm{~g} \mathrm{~L}^{-1}\right)$, iso-butyric $\left(10 \mathrm{~g} \mathrm{~L}^{-1}\right)$, propionic $\left(2 \mathrm{~g} \mathrm{~L}^{-1}\right)$, valeric $\left(0.22 \mathrm{~g} \mathrm{~L}^{-1}\right)$ and hexanoic acids $\left(0.05 \mathrm{~g} \mathrm{~L}^{-1}\right)$. Valeric and hexanoic acids were only detected during the batch phase and the following two HRTs. After the fourth HRT, the SC1 reactor showed a steady reduction in the production of $n$-butyric acid, although the production of the other acids was stable until the seventh HRT. During the last two HRTs, the production of these acids was also reduced in similar pattern as that of $n$-butyric acid. The SC2 reactor exhibited the second highest production of VFA (70 $\left.\mathrm{g} \mathrm{L}^{-1}\right)$ after the $\mathrm{SC} 1$ reactor. SC2 formed all the VFAs during the first HRT (Fig. 4b); however, when the reactor was more stable, it only produced acetic (30\%), 

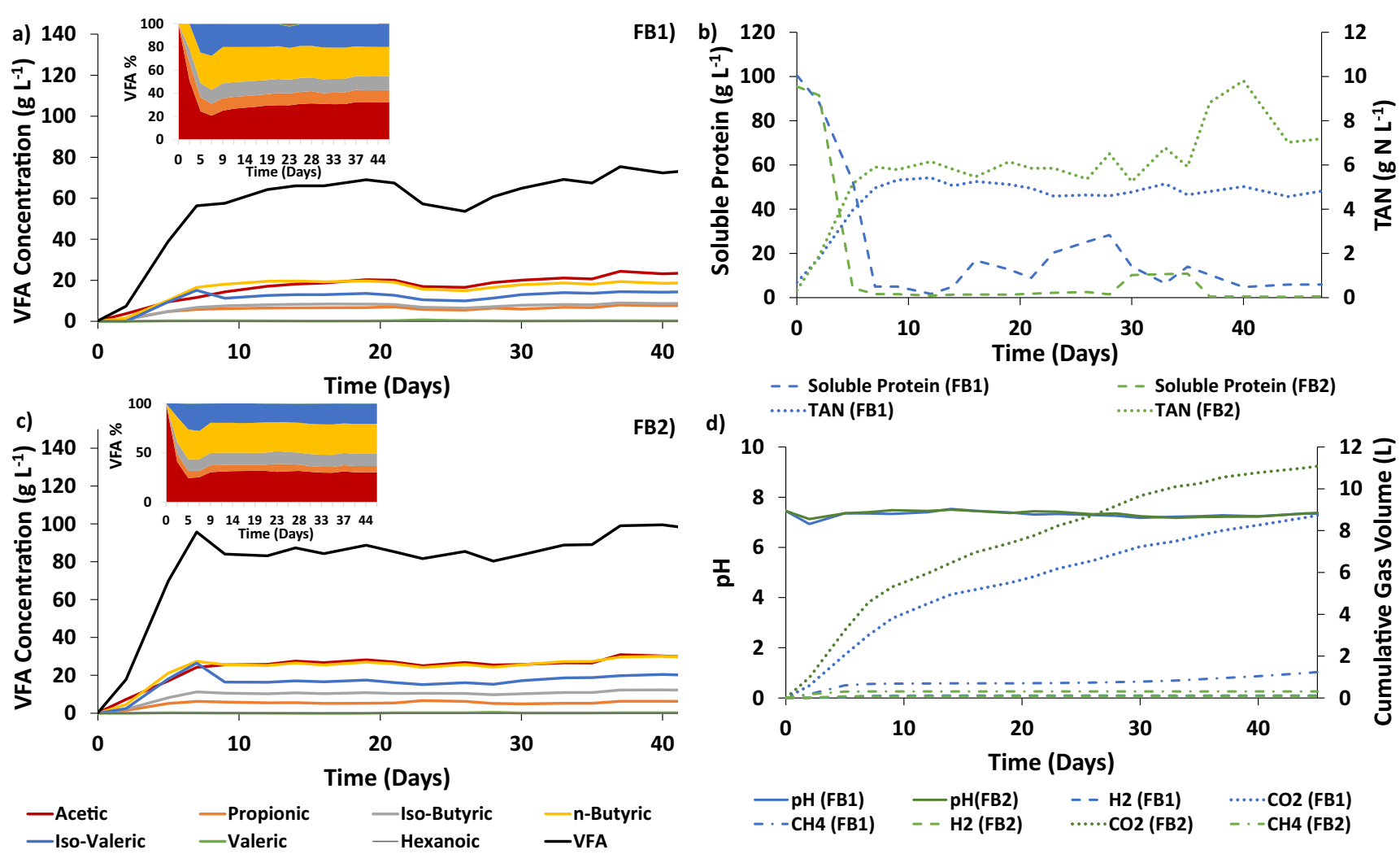

Fig. 3 Fed-batch experiment a VFA profile of reactor FB1; the embedded image corresponds to the VFA composition. $\mathbf{b}$ VFA profile of reactor FB2; the embedded image corresponds to the VFA composition. $\mathbf{c}$ Protein consumption and TAN concentration d) Cumulative gas production and $\mathrm{pH}$

propionic (5\%), $n$-butyric (30\%), iso-butyric (15\%) and isovaleric acids (20\%). The total VFA production and its profile in $\mathrm{SC} 2$ were roughly stable during the entire course of the experiment. The SC3 reactor was the steadiest reactor (Fig. $4 \mathrm{c})$, but its VFA production $\left(40 \mathrm{~g} \mathrm{~L}^{-1}\right)$ was lower than other reactors. The VFA profile in $\mathrm{SC} 3$ was similar to $\mathrm{SC} 1$ and $\mathrm{SC} 2$, with acetic (30\%), propionic (5\%), $n$-butyric (30\%), isobutyric (15\%), and iso-valeric (20\%) acids. No significant drop in VFA production was found in this reactor. SC4 reactor had a different and more dynamic behaviour compared with other reactors. This reactor exhibited a very high VFA peak of $85 \mathrm{~g} \mathrm{~L}^{-1}$ towards the end of the second HRT, and the VFA concentration declined to a stable level of around $50 \mathrm{~g} \mathrm{~L}^{-1}$ from the fourth HRT until the end of the fermentation. The acid composition was similar to the other reactors, acetic (30\%), propionic $(5 \%), n$-butyric $(30 \%)$, iso-butyric (15\%) and iso-valeric (20\%) acids; although at the initial HRTs, a larger proportion of acetic acid was obtained.

SC1 exhibited a steady protein consumption (Fig. 5a) when the reactor was having a stable production of VFA (the first seven HRTs), after that, the protein concentration increased from approximately 2 to $40 \mathrm{~g} \mathrm{~L}^{-1}$ towards the end of experiment. As a result, $\mathrm{SC} 1$ had a TAN concentration between 4 and $6 \mathrm{~g} \mathrm{~L}^{-1}$ during the first seven HRTs but it decreased to $2.5 \mathrm{~g} \mathrm{~L}^{-1}$ after that (Fig. 5a). The protein consumption in $\mathrm{SC} 2$ was stable during the majority of the fermentation process, although an increase in protein concentration was observed at the final HRT. This trend was also confirmed by the ammonia concentration and $\mathrm{pH}$ of this reactor. TAN had a concentration between 3.5 and $5 \mathrm{~g} \mathrm{~L}^{-1}$, and the $\mathrm{pH}$ fluctuated between 6.6 and 7 in SC2 before the final HRT. In SC3 (Fig. 5c), the soluble protein $\left(60 \mathrm{~g} \mathrm{~L}^{-1}\right)$ was higher than that of the other reactors and its TAN concentration was lower $\left(2.8-3.5 \mathrm{~g} \mathrm{~L}^{-1}\right)$, reflecting the less efficient VFA production. Low protein concentration $\left(1 \mathrm{~g} \mathrm{~L}^{-1}\right)$ and high TAN concentration $\left(5 \mathrm{~g} \mathrm{~L}^{-1}\right)$ were obtained in SC4 during the first two HRTs. After that, protein concentration increased and stabilised at a concentration around $55 \mathrm{~g} \mathrm{~L}^{-1}$, and the TAN concentration decreased to values between 3 and $3.5 \mathrm{~g} \mathrm{~L}^{-1}$ in the meanwhile. The steady-state performance of $\mathrm{SC} 4$ was similar as that of reactor $\mathrm{SC} 3$, indicating that a negative effect was created by the combination of a semi-continuous operation and the enzymatic pre-treatment. Along with its function of enzymatic hydrolysis for protein-rich substrate, trypsin also has potential to cleaving microbial cell surface proteins and affecting its functioning over time (Huang et al. 2010). It appeared that this antagonistic effect became evident after 2 weeks of operation, as shown in Fig. 4. This did not affect batch fermentation because all VFA had already been produced over the initial 2 weeks of operation; however, this caused severe damage to long-term continuous system. 

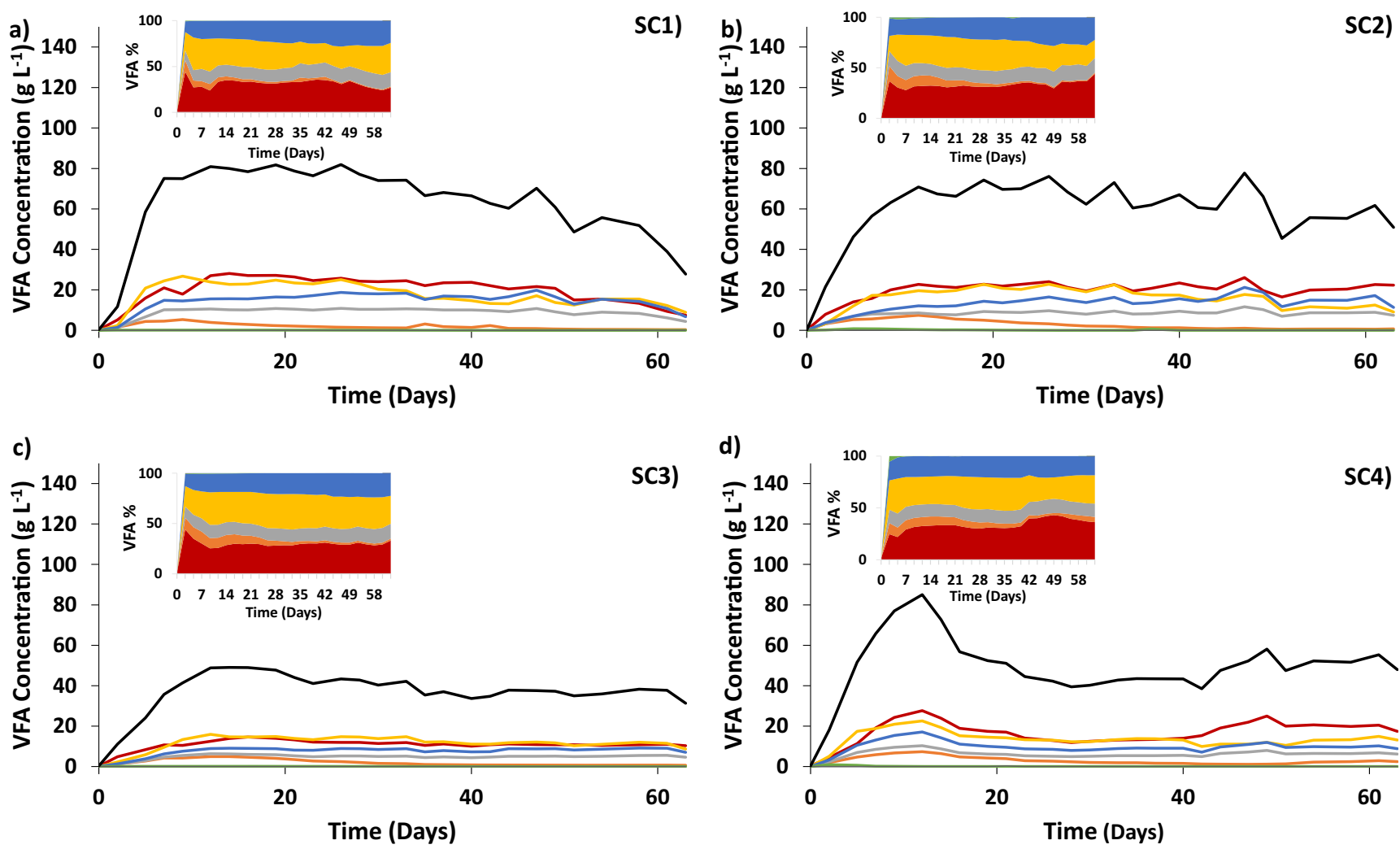

\section{-Acetic - Propionic - Iso-Butyric - n-Butyric - Iso-Valeric - Valeric - Hexanoic -VFA}

Fig. 4 VFA profiles of the semi-continuous experiment. a Reactor SC1. b Reactor SC2. $\mathbf{c}$ Reactor SC3. d Reactor SC4

The $\mathrm{SC} 1$ gas phase (Fig. 5b) mainly composed of $\mathrm{CO}_{2}$ followed by $\mathrm{H}_{2} \cdot \mathrm{CH}_{4}$ was not detected in this reactor after the semi-continuous mode started. The reactor SC2 (Fig. 5b) produced smaller but constant amounts of $\mathrm{CO}_{2}$ and $\mathrm{H}_{2}$. Similar to reactor $\mathrm{SC} 1, \mathrm{CO}_{2}$ was the gas with the greatest concentration and $\mathrm{CH}_{4}$ was not found after the initial phase. $\mathrm{SC} 3$ achieved lower amounts of $\mathrm{CO}_{2}, \mathrm{CH}_{4}$, and $\mathrm{H}_{2}$ (Fig. 5d) compared with other reactors. This reactor generated all three gases during the entire course of experiment, and the principal gas was $\mathrm{CO}_{2}$, followed by $\mathrm{CH}_{4}$ and $\mathrm{H}_{2}$. The initial gas production in reactor $\mathrm{SC} 4$ was the greatest among all reactors, but the gas production was reduced drastically later on. SC4 also produced all three gases throughout the fermentation process. It is worth noting that the $\mathrm{CH}_{4}$ produced in $\mathrm{SC} 3$ and $\mathrm{SC} 4$ was negligible compared with the loss of VFA production potential, and therefore, it is not the cause of the reduced VFA production in these two reactors.

Table 3 shows the daily VFA production yield calculated using equations in the supplementary material. $\mathrm{SC} 1$ and $\mathrm{SC} 2$ had the higher average daily VFA production rate and yield, but they were less stable. This evidenced the wide difference between their maximum and minimum production rates and their standard deviation, with propionic acid having the largest variation. $\mathrm{SC} 1$ and $\mathrm{SC} 2$ had daily average yields above $45 \%$, whereas SC3 and SC4 were below 40\%. The low yield of SC3 (30\%) correlates with the results exhibited in Figs. 4 and 5. In general, the VFA yield of semi-continuous reactors (30-50\%) was lower than that of batch (55-60\%) and fed-batch (60$70 \%$ ) reactors, due to the shorter retention time of semicontinuous experiment.

\subsection{Microbial community analysis}

The microbial community analysis was performed for the reactors $\mathrm{FB} 2$ (EH) and SC3 (BL 90\% and $\mathrm{EH}$ ), where the reactor FB2 achieved the highest VFA yield, and the reactor SC3 was the most stable reactor in the semi-continuous operation. In both samples, $99.6 \%$ of the sequences were assigned to five phyla, Firmicutes, Proteobacteria, Synergistetes, Actinobacteria and Bacteroidetes (Fig. 6). The additional $0.4 \%$ of the sequences, however, was not allocated to any specific phylum. Among the five phyla identified, Firmicutes was the most dominant one with more than $99.5 \%$ abundance of their individual microbial community; this value indicates the strong participation of this phylum in the conversion of proteins to VFA in mixed-culture anaerobic fermentation. At the order level (Fig. 6), both samples had more than 20 orders present: eight and nine of them were from the Firmicutes phylum in FB2 and SC3, respectively. Six 

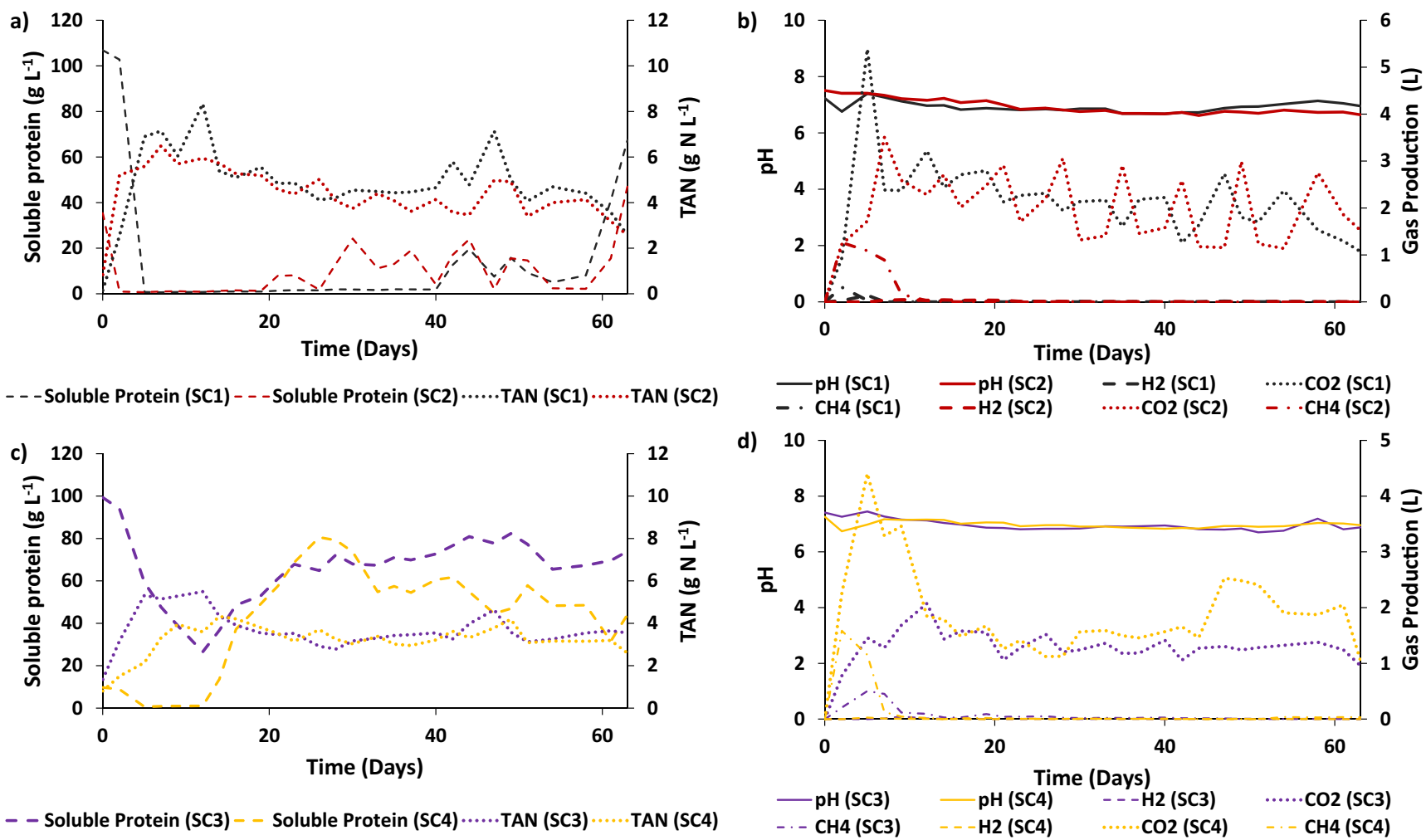

- - Soluble Protein (SC3) - - Soluble Protein (SC4) ...... TAN (SC3) ….. TAN (SC4)

Fig. 5 Soluble protein, TAN, gas production and $\mathrm{pH}$ of semi-continuous experiment. a Soluble protein and TAN concentrations of reactors SC1 and $\mathrm{SC} 2$. b Gas production and $\mathrm{pH}$ of reactors $\mathrm{SC} 1$ and $\mathrm{SC} 2$; gas production data represent the $\mathrm{CO}_{2}, \mathrm{H}_{2}$ and $\mathrm{CH}_{4}$ produced during each

of SC2 feeding cycle. c Soluble protein and TAN concentrations of reactors $\mathrm{SC} 3$ and $\mathrm{SC} 4$. d Gas production and $\mathrm{pH}$ of reactors $\mathrm{SC} 3$ and $\mathrm{SC} 4$; gas production data represent the $\mathrm{CO}_{2}, \mathrm{H}_{2}$ and $\mathrm{CH}_{4}$ produced during each of SC4 feeding cycle

orders were identified in this phylum: Bacillales, Lactobacillales, Clostridiales, MBA08, Natranaerobiales, Thermoanaerobacterales and two (FB2) and three (SC3)

unclassified orders. Where the unclassified orders were identified in upper taxa, two of them were from the clostridia and OPB450 class and another one with only Firmicutes phylum

Table 3 Daily production rate and VFA yields for the semi-continuous reactor experiment

\begin{tabular}{|c|c|c|c|c|c|c|c|c|c|c|c|c|}
\hline \multirow[t]{3}{*}{ Volatile fatty acids } & \multicolumn{12}{|c|}{ Production rate $\left(\mathrm{g} \mathrm{L}^{-1} \cdot \mathrm{d}^{-1}\right)$} \\
\hline & \multicolumn{3}{|l|}{$\mathrm{SC} 1$} & \multicolumn{3}{|l|}{$\mathrm{SC} 2$} & \multicolumn{3}{|l|}{$\mathrm{SC} 3$} & \multicolumn{3}{|l|}{$\mathrm{SC} 4$} \\
\hline & Average & Max. & Min. & Average & Max. & Min. & Average & Max. & Min. & Average & Max. & Min. \\
\hline Acetic acid & $2.8 \pm 1.4$ & 5.0 & 0.1 & $3.0 \pm 0.8$ & 4.7 & 1.1 & $1.6 \pm 0.5$ & 2.8 & 0.9 & $2.6 \pm 1.3$ & 5.8 & 1.2 \\
\hline Propionic acid & $0.2 \pm 0.4$ & 1.2 & -0.3 & $0.4 \pm 0.5$ & 1.6 & 0.01 & $0.2 \pm 0.2$ & 0.8 & 0.02 & $0.4 \pm 0.4$ & 1.4 & 0.1 \\
\hline Iso-butyric acid & $1.3 \pm 0.5$ & 1.7 & 0.1 & $1.2 \pm 0.4$ & 2.0 & 0.034 & $0.7 \pm 0.2$ & 1.2 & 0.4 & $1.0 \pm 0.5$ & 1.9 & 0.5 \\
\hline$n$-Butyric acid & $2.4 \pm 1.2$ & 5.2 & 0.3 & $2.4 \pm 1.1$ & 4.6 & -0.7 & $1.8 \pm 0.6$ & 3.5 & 0.5 & $2.1 \pm 0.9$ & 4.7 & 0.6 \\
\hline Iso-valeric acid & $2.1 \pm 0.9$ & 3.4 & -0.2 & $1.9 \pm 0.8$ & 3.6 & -0.4 & $1.2 \pm 0.3$ & 1.9 & 0.5 & $1.5 \pm 0.7$ & 3.3 & 0.5 \\
\hline Total VFA & $8.8 \pm 3.5$ & 12.9 & 0.8 & $9.0 \pm 2.8$ & 12.7 & 0.5 & $5574 \pm 1659$ & 8.7 & 3.0 & $7.6 \pm 3.5$ & 16.5 & 4.0 \\
\hline \multirow[t]{3}{*}{ Volatile Fatty Acids } & \multicolumn{12}{|c|}{ Yield ( $\mathrm{g}^{-1} \mathrm{VFA} \mathrm{g}^{-1}$ VS) } \\
\hline & $\mathrm{SC} 1$ & & & $\mathrm{SC} 2$ & & & $\mathrm{SC} 3$ & & & $\mathrm{SC} 4$ & & \\
\hline & Average & Max. & Min. & Average & Max. & Min. & Average & Max. & Min. & Average & Max. & Min. \\
\hline Acetic acid & $0.149 \pm 0.073$ & 0.337 & 0.009 & $0.164 \pm 0.050$ & 0.279 & 0.049 & $0.086 \pm 0.018$ & 0.125 & 0.056 & $0.138 \pm 0.063$ & 0.260 & 0.061 \\
\hline Propionic acid & $0.010 \pm 0.016$ & 0.052 & 0.000 & $0.021 \pm 0.023$ & 0.072 & 0.001 & $0.012 \pm 0.012$ & 0.048 & 0.001 & $0.024 \pm 0.021$ & 0.077 & 0.004 \\
\hline Iso-butyric acid & $0.067 \pm 0.024$ & 0.103 & 0.005 & $0.067 \pm 0.026$ & 0.133 & 0.002 & $0.039 \pm 0.009$ & 0.060 & 0.021 & $0.051 \pm 0.024$ & 0.122 & 0.021 \\
\hline$n$-Butyric acid & $0.126 \pm 0.058$ & 0.234 & 0.014 & $0.127 \pm 0.062$ & 0.222 & 0.000 & $0.094 \pm 0.031$ & 0.157 & 0.022 & $0.111 \pm 0.056$ & 0.314 & 0.025 \\
\hline Iso-valeric acid & $0.111 \pm 0.047$ & 0.195 & 0.000 & $0.107 \pm 0.052$ & 0.242 & 0.000 & $0.063 \pm 0.015$ & 0.087 & 0.023 & $0.080 \pm 0.040$ & 0.188 & 0.023 \\
\hline Total VFA & $0.464 \pm 0.178$ & 0.690 & 0.037 & $0.488 \pm 0.175$ & 0.844 & 0.024 & $0.294 \pm 0.075$ & 0.473 & 0.136 & $0.404 \pm 0.185$ & 0.887 & 0.181 \\
\hline
\end{tabular}


a)

Clostridiales (C) OPB54 (Unidentified) (K) Bacteria (Unidentified) (C) Clostridia (Unidentified) MBA08

(P) Firmicutes (Unidentified) Lactobacillales Bacillales Bacteroidales Flavobacteriales Enterobacteriales

Synergistales Unclassified

(C) Gammaproteobacteria (Unidentified) Rickettsiales BSA2B-08 Bifidobacteriales (C) Actinobacteria (Unidentified) Oceanospirillales Alteromonadales Burkholderiales (P) Proteobacteria (Unidentified)

(P) Bacteroidetes (Unidentified) Actinomycetales Thermoanaerobacterales

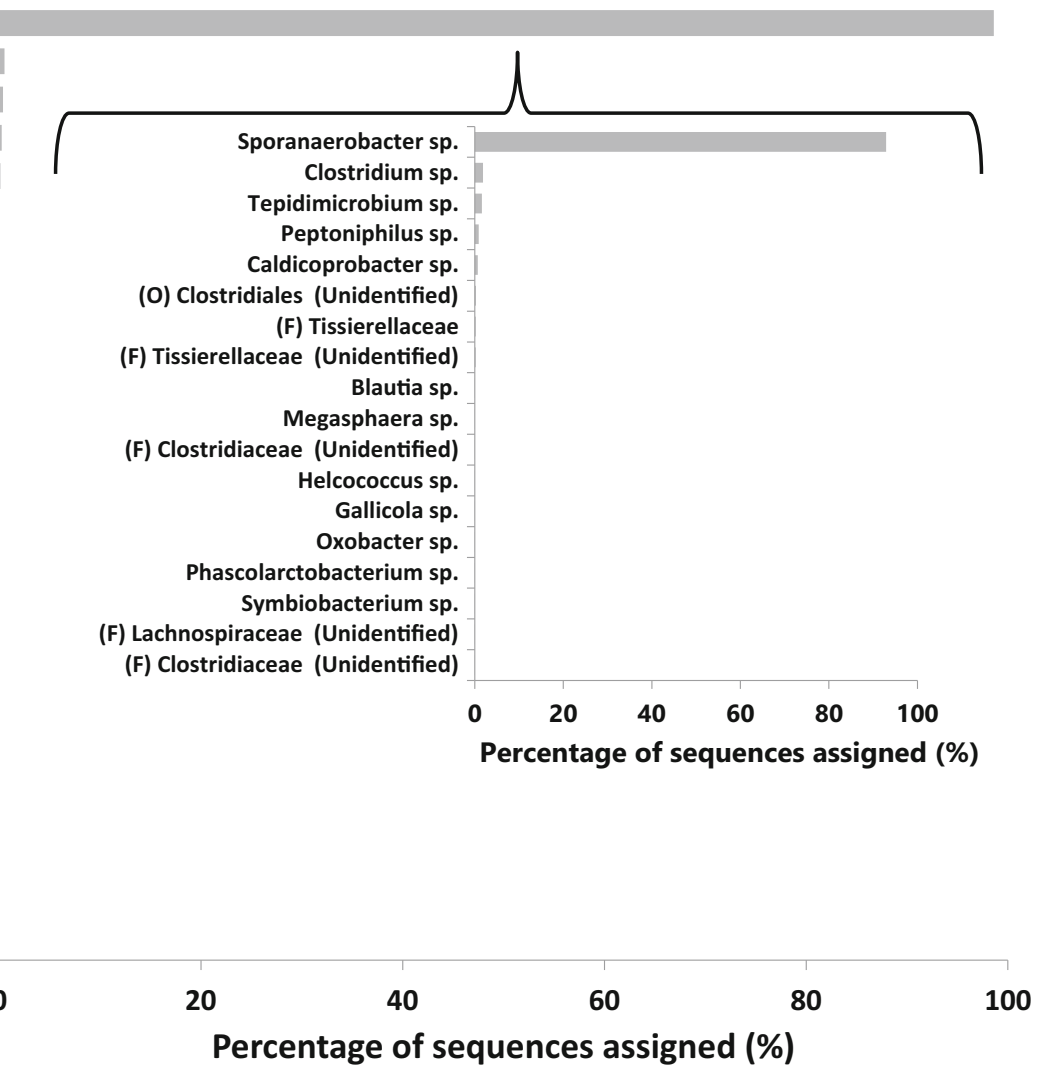

Percentage of sequences assigned (\%)

b)

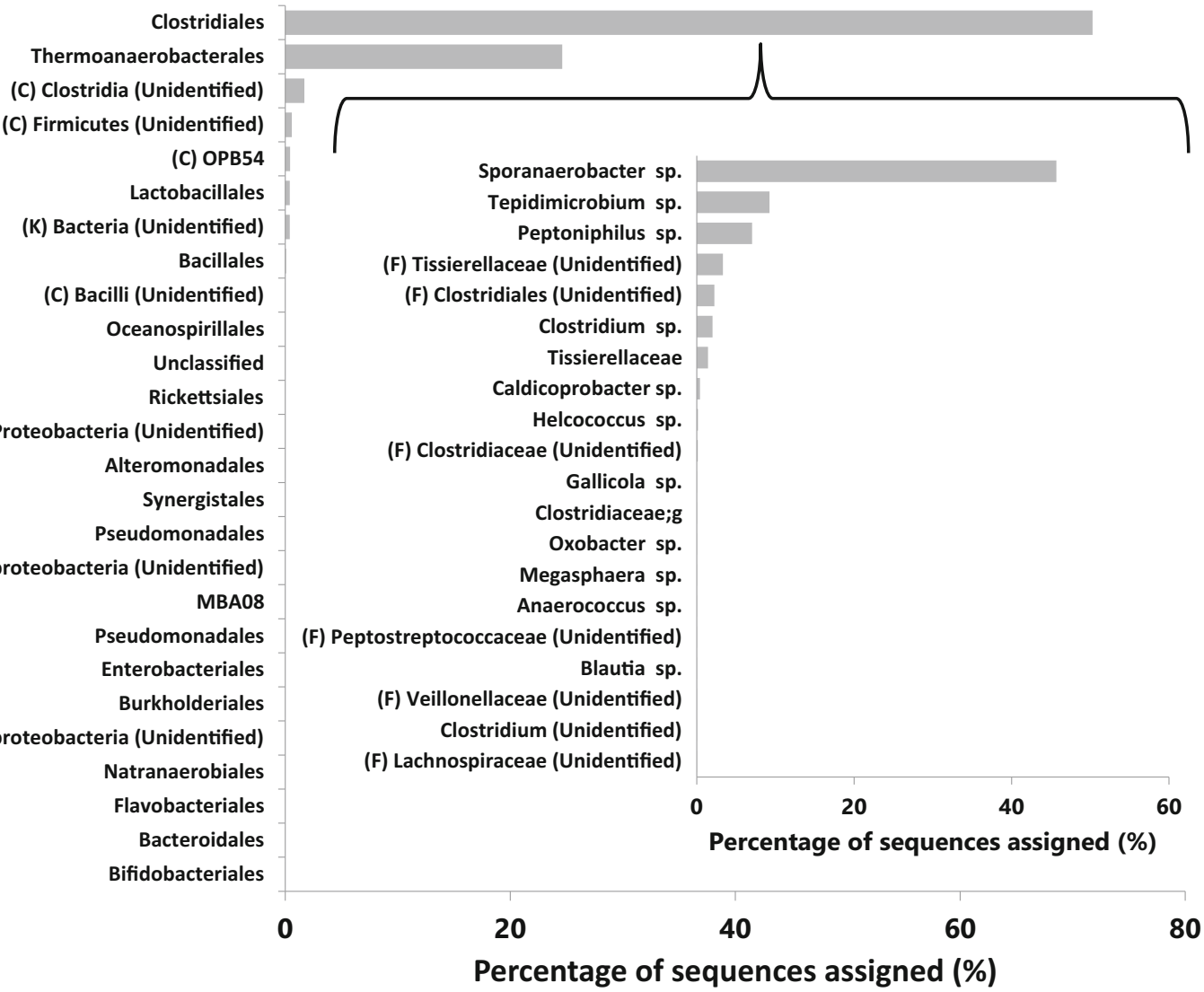

Percentage of sequences assigned (\%) 
Fig. 6 Percentage of sequences assigned to order, the embedded plot is the sequences assigned to the genus level for the Clostridiales order a reactor $\mathrm{SC} 3$ and $\mathbf{b}$ reactor $\mathrm{FB} 2$

assignation. The major difference between both reactors occurred in the Clostridiales order. In both reactors, the order of Clostridiales obtained the greatest percentage (SC3 98.6\%, FB2 $71.8 \%$ ), but the community structure of this order was different in these two reactors: FB2 has seven genus with more than $1 \%$ of sequences assigned, whereas SC3 had only a subsection of them (Sporanaerobacter sp., Tepidimicrobium sp. and Clostridium sp.). Among them, Sporanaerobacter sp. was the genus that included the majority of the sequences in FB2 (49\%) and SC3 (92\%), and its high participation indicated that members from this genus were closely associated with the conversion of proteins to VFA. The second major difference between two reactors lied with the order of Thermoanaerobacterales. The abundance of this order in SC3 was just $0.53 \%$, compared with $24.6 \%$ in FB2. Although Thermoanaerobacterales is the second largest order in FB2, $99.9 \%$ of its sequences were assigned to two unidentified families.

\section{Discussion}

The VFA production using mixed-culture anaerobic fermentation of slaughterhouse blood was demonstrated feasible. The results obtained in this study using slaughterhouse blood as singular substrate achieved the highest VFA concentration up to $100 \mathrm{~g} \mathrm{~L}^{-1}$. This VFA concentration is several times greater than the reported values $\left(10 \sim 20 \mathrm{~g} \mathrm{~L}^{-1}\right)$ by previous studies using other types of waste streams. For instance, the VFA concentrations reached up to $20 \mathrm{~g} \mathrm{~L}^{-1}$ when using lignocellulosic material such as paper wastes [6], and maize silage [16] as substrates. Waste biomass such as food waste (Resulting VFA concentration $20 \mathrm{~g} \mathrm{~L}^{-1}$ ) [17], mixture of waste activated sludge and henna plant biomass (11 $\left.\mathrm{g} \mathrm{L}^{-1}\right)$ [18], glycerol (16 $\left.\mathrm{g} \mathrm{L}^{-1}\right)$ [8] and cheese whey (20 $\mathrm{g} \mathrm{L}^{-1}$ ) [16] have also been used for VFA production, with concentrations considerably lower than what obtained in this study with slaughterhouse blood. The high VFA concentration achieved in this work can be attributed to the sufficient buffering capacity in the fermenters which is provided by the high concentration of TAN in the system [4]. Therefore, compared with lignocellulosic substrates, one main advantage of using high nitrogen substrates such as slaughterhouse blood is the simultaneous TAN and VFA production during acidogenesis. The resulting high TAN concentration in the fermentation broth provides two important functions, i.e. buffering capacity and methanogens inhibition, which are usually achieved by external input when lignocellulosic materials are in use [6-9]. These additional requirements increase the operating cost and the order of process complexity in terms of ancillary units and system control.

Compared with anaerobic digestion for biogas production, the selection of the substrate loading (e.g. substrate to inoculum ratio for batch mode or organic loading rate for (semi-)continuous mode) has less constrains with regard to fermentative VFA production. The substrate to inoculum ratio is usually less than 1 on a VS basis for batch digestion [19] and less than $8 \mathrm{~g} \mathrm{VS} \mathrm{L}^{-1}$ day $^{-1}$ for continuous digestion operation [20]. This is because the conversion rates of acidogenesis, acetogenesis and methanogenesis have to be well controlled in that process to prevent the accumulation of intermediate production such as VFA and the inhibition of methanogens. This is, however, not the case for VFA production via fermentation. As can be concluded from the preliminary experiment (supplementary material) and semi-continuous trial, the higher blood loading (corresponding to higher substrate to inoculum ratio or higher organic loading rate) provided higher VFA production rate and final VFA concentration, also inhibited to a greater extent the methane production. The highest volumetric substrate to inoculum loading used in this study was 9 , corresponding to a ratio of 50 on a VS basis and a final VFA concentration up to $100 \mathrm{~g} \mathrm{~L}^{-1}$. The lower final VFA concentration (< $20 \mathrm{~g} \mathrm{~L}^{-1}$ ) from other studies using wastes such as food waste [17], maize silage, cheese whey, and microalgae biomass [16] may be caused by the low substrate to inoculum ratio used (50\% inoculum on a volume basis) [16].

Enzymatic hydrolysis appeared to have a positive effect on batch and fed-batch operation and the hydrolysed substrate was degraded to VFA at faster rate and to a greater extent, and especially facilitated acetic acid production. Its negative effect, however, was detected in the semi-continuous reactors (SC3 and SC4): the VFA concentration drop correlated with the trypsin concentration. In batch operation, trypsin was only added in the initial load and its activity decreased through the fermentation as results of trypsin denaturation, microbial trypsin inhibitors, or microbial proteases $[21,22]$. In contrast, in the semi-continuous reactors, the continuing addition of hydrolysed blood with trypsin into reactors generated a negative effect by degrading proteins of microorganisms [23, 24]. In the fed-batch reactors, the addition rate of hydrolysed blood with trypsin was much lower than that of the semi-continuous reactors; therefore, its activity reduction rate was probably higher than the amount of trypsin addition avoiding the negative effects observed in the semicontinuous reactors. Therefore, for (semi)-continuous operation, the other pre-treatment methods should be used to facilitate the rate and extent of VFA production, such as heat-alkaline pre-treatment [25] and ultraviolet pretreatment [26]. 
The microbial community analysis proved the importance of the Firmicutes phylum and its Clostridiales order in the transformation of proteins into VFA at high concentrations, consistent with the results of bacteria community composition analysis of digester using pig blood as substrate [5]. The differences between the fed-batch and semi-continuous reactor community may be explained by the duplication rate of relevant microorganisms. In fed-batch operation, the duplication rate is not a selection mechanism because the medium is not removed from the reactor; therefore, microbes with low duplication rate but adaptability to the reactor conditions can flourish. In contrast, the semi-continuous reactor requires microorganisms with a doubling time much shorter than the HRT; otherwise, they are just washed out of the reactor over time.

In terms of operation mode comparison, the batch fermenters with acclimated inoculum and the fed-batch fermenters achieved the highest concentration of VFA $\left(100 \mathrm{~g} \mathrm{~L}^{-1}\right)$ at an initial blood loading of $122 \mathrm{~g}$ blood VS L ${ }^{-1}$, indicating a conversion rate of $0.82 \mathrm{~g} \mathrm{VFA} \mathrm{g}^{-1}$ VS. This high level of VFA concentration was expected mainly because the duration of the experiments ( 45 days) allowed the conversion process to proceed to a greater extent than the semi-continuous mode. The reduced concentration of VFA produced in semicontinuous fermenters versus fed-batch was caused by the much shorter hydraulic retention time (7 days). The bestperformed semi-continuous reactor (SC2) achieved a total VFA production of $444 \mathrm{~g}$ of VFA L ${ }^{-1}$ over the initial 45 days of its operation, which correspond to a conversion of $0.51 \mathrm{~g}$ VFA $\mathrm{g}^{-1}$ blood VS. The production capacity of the semicontinuous operation was therefore considerably longer than that of the batch and fed-batch reactors. It is important to point out that in batch processes, $80 \%$ of the total VFA production is achieved by day 10 . If the batch fermentation is performed only during the initial 10 days, a larger VFA production can be achieved. Batch processes can be improved by reducing the fermentation time, although this VFA increment is achieved at the expense of lower blood conversion rate. Similarly, to improve semi-continuous production, it is necessary to evaluate if longer HRT can result in a more efficient process in the semi-continuous reactors.

The result obtained in this study demonstrates a fermentation process capable to produce a VFA concentration much higher than the feasibility threshold for an industrial process. The MixAlco process is a technology that transforms any biodegradable material into alcohol based principally on VFA production. The MixAlco process needs a minimum VFA concentration of $22 \mathrm{~g} \mathrm{~L}^{-1}$ to achieve the low cost for VFA fermentation and purification processes [9, 27]. The VFA production achieved in this research by the transformation of slaughterhouse blood is 2 5 times higher than that threshold level. The high VFA production achieved has also stimulated new research on alternative feasible industrial downstream processing, and the preliminary study on the initial steps of VFA recovery was performed using esterification and a membrane solventbased extraction [28]. Both techniques achieved similar recovery comparable to other purification processes [29-31], and each of them had specific features to be preferably integrated with different operation mode(s) demonstrated in this research. Batch and fed-batch processes were more suitable for esterification recovery because untransformed blood proteins remained in fermentation froth were much less compared with semi-continuous fermentation. The advantage of this approach is the possibility of producing VFA methyl esters and ammonium sulphate simultaneously, with the first an important product for the scents and fragrance industry, and the second a well-known fertiliser. The principal drawback of esterification recovery is that it requires a high VFA concentration (above $80 \%$ ). In contrast, the solvent-based membrane system is a better fit for the continuous fermentation process because it selectively recovers butyric and iso-valeric acids ( $>80 \%$ ) in favour of acetic acid $(5 \%)$, reduces the product-induced inhibition effect on longer-chain VFA and allows the utilisation of acetic acid in recycled stream. Additionally, this method is a less expensive option compared with water removal processes such as distillation. The issue of this method is the use of organic solvents (octanol), although adding a stripper membrane step into the recovery process can recover and reuse these solvents. In the future research, the economic feasibility of the process needs to be confirmed by using processmodelling software.

\section{Conclusions}

Anaerobic mixed-culture fermentation is a suitable technology to transform slaughterhouse blood into high concentrations of VFA (45-100 $\left.\mathrm{g} \mathrm{L}^{-1}\right)$. In this process, the VFA produced were mainly acetic, $n$-butyric, iso-valeric, iso-butyric and propionic acids. Blood loading and inoculum acclimation were the main factors that influenced the VFA concentration. Enzymatic hydrolysis improved the initial production rate; however, it did not affect the final VFA concentration and was inhibitory in the semi-continuous reactors. Iodoform increased the VFA production in the low blood loading and modified the VFA profile in the high blood loadings. The batch and semi-continuous reactor generated good results in terms of total VFA production and yield, and the selection of operation mode should be based on the analysis of the economic and logistic parameters and the downstream recovery unit of the system. These results pave a way for the development of future cost-effective processes to produce VFA from slaughterhouse blood and to increase the economic and environmental feasibility of a VFA bio-refinery from high-protein wastes. 
Funding information The authors thank the UK Biotechnology and Biological Sciences Research Council (BBSRC) and the Anaerobic Digestion network (ADNet) for funding this project (POC2014016). Dr. Jersson Plácido would like to thank the financial support provided by the European Regional Development Fund / Welsh Government funded BEACON research program (Swansea University). Data supporting this study are openly available from the University of Southampton repository at https://doi.org/10.5258/SOTON/D0482.

\section{Compliance with ethical standards}

Conflict of interest The authors declare that they have no conflict of interest.

Open Access This article is distributed under the terms of the Creative Commons Attribution 4.0 International License (http:// creativecommons.org/licenses/by/4.0/), which permits unrestricted use, distribution, and reproduction in any medium, provided you give appropriate credit to the original author(s) and the source, provide a link to the Creative Commons license, and indicate if changes were made.

Publisher's Note Springer Nature remains neutral with regard to jurisdictional claims in published maps and institutional affiliations.

\section{References}

1. Marquer P, Rabade T, Forti R (2014) Meat production statistics. Eurostat. http://ec.europa.eu/eurostat/statistics-explained/index.php/ Meat_production_statistics\#Further_Eurostat_information 2015.

2. Marcos A, Al-Kassir A, Mohamad AA, Cuadros F, LópezRodríguez F (2010) Combustible gas production (methane) and biodegradation of solid and liquid mixtures of meat industry wastes. Appl Energy 87:1729-1735. https://doi.org/10.1016/j. apenergy.2009.09.037.

3. Hejnfelt A, Angelidaki I (2009) Anaerobic digestion of slaughterhouse by-products. Biomass Bioenergy 33:1046-1054. https://doi. org/10.1016/j.biombioe.2009.03.004

4. Zhang Y, Banks CJ (2012) Co-digestion of the mechanically recovered organic fraction of municipal solid waste with slaughterhouse wastes. Biochem Eng J 68:129-137. https://doi.org/10.1016/j.bej. 2012.07.017.

5. Kovács E, Wirth R, Maróti G, Bagi Z, Rákhely G, Kovács KL (2013) Biogas production from protein-rich biomass: fed-batch anaerobic fermentation of casein and of pig blood and associated changes in microbial community composition. PLos ONE 8: e77265

6. Forrest AK, Hollister EB, Gentry TJ, Wilkinson HH, Holtzapple MT (2012) Comparison of mixed-acid fermentations inoculated with six different mixed cultures. Bioresour Technol 118:343349. https://doi.org/10.1016/j.biortech.2012.05.043.

7. Fu Z, Holtzapple MT (2010) Consolidated bioprocessing of sugarcane bagasse and chicken manure to ammonium carboxylates by a mixed culture of marine microorganisms. Bioresour Technol 101: 2825-2836. https://doi.org/10.1016/j.biortech.2009.11.104

8. Forrest AK, Sierra R, Holtzapple MT (2010) Effect of biodiesel glycerol type and fermentor configuration on mixed-acid fermentations. Bioresour Technol 101:9185-9189. https://doi.org/10.1016/j. biortech.2010.07.041.

9. Domke SB, Aiello-Mazzarri C, Holtzapple MT (2004) Mixed acid fermentation of paper fines and industrial biosludge. Bioresour Technol 91:41-51. https://doi.org/10.1016/S0960-8524(03)00156-1.
10. Bah CS, Bekhit AEA, Carne A, McConnell MA (2013) Slaughterhouse blood: an emerging source of bioactive compounds 12:314-331

11. Sigma-Aldrich (2013) Product information: trypsin solution from porcine pancreas. https:/www.sigmaaldrich.com/content/dam/ sigma-aldrich/docs/Sigma/Product_Information_Sheet/1/t4549pis. pdf. Accessed 28 Mar 2018.

12. Walker M, Zhang Y, Heaven S, Banks C (2009) Potential errors in the quantitative evaluation of biogas production in anaerobic digestion processes. Bioresour Technol 100:6339-6346

13. Caporaso JG, Lauber CL, Walters WA, Berg-Lyons D, Lozupone CA, Turnbaugh PJ, Fierer N, Knight R (2011) Global patterns of $16 \mathrm{~S}$ rRNA diversity at a depth of millions of sequences per sample. Proc Natl Acad Sci U S A 108(Suppl 1):4516-4522. https://doi.org/ 10.1073/pnas. 1000080107 [doi].

14. Apprill A, McNally S, Parsons R, Webe L (2015) Minor revision to V4 region SSU rRNA 806R gene primer greatly increases detection of SAR11 bacterioplankton

15. Parada AE, Needham DM, Fuhrman JA (2015) Every base matters: assessing small subunit rRNA primers for marine microbiomes with mock communities, time series and global field samples. Environ Microbiol

16. Jankowska E, Chwialkowska J, Stodolny M, Oleskowicz-Popiel P (2017) Volatile fatty acids production during mixed culture fermentation - the impact of substrate complexity and $\mathrm{pH}$. Chem Eng J 326:901-910

17. Stein UH, Wimmer B, Ortner M, Fuchs W, Bochmann G (2017) Maximizing the production of butyric acid from food waste as a precursor for ABE-fermentation. Sci Total Environ 598:993-1000

18. Huang J, Zhou R, Chen J, Han W, Chen Y, Wen Y, Tang J (2016) Volatile fatty acids produced by co-fermentation of waste activated sludge and henna plant biomass. Bioresour Technol 211:80-86

19. Raposo F, Fernández-Cegrí V, De la Rubia M, Borja R, Béline F, Cavinato C, Demirer G, Fernández B, Fernández-Polanco M, Frigon J (2011) Biochemical methane potential (BMP) of solid organic substrates: evaluation of anaerobic biodegradability using data from an international interlaboratory study. J Chem Technol Biotechnol 86:1088-1098

20. Liu C, Wang W, Anwar N, Ma Z, Liu G, Zhang R (2017) Effect of organic loading rate on anaerobic digestion of food waste under mesophilic and thermophilic conditions. Energy Fuel 31:29762984

21. Murthy S, Kostman J, Dinoso VP (1980) Effect of pH, substrate, and temperature on tryptic activity of duodenal samples. Dig Dis Sci 25:289-294

22. Grenier D (1991) Production of trypsin and chymotrypsin inhibitors by oral bacterial isolates. J Periodont Res 26:381-387

23. Goldberg AL (1972) Correlation between rates of degradation of bacterial proteins in vivo and their sensitivity to proteases. Proc Natl Acad Sci U S A 69:2640-2644

24. Sekirov I, Russell SL, Antunes LC, Finlay BB (2010) Gut microbiota in health and disease. Physiol Rev 90:859-904. https://doi. org/10.1152/physrev.00045.2009 [doi].

25. Wang X, Li Y, Liu J, Ren N, Qu J (2016) Augmentation of proteinderived acetic acid production by heat-alkaline-induced changes in protein structure and conformation. Water Res 88:595-603

26. Xiao N, Chen Y, Ren H (2013) Altering protein conformation to improve fermentative hydrogen production from protein wastewater. Water Res 47:5700-5707. https://doi.org/10.1016/j.watres. 2013.06.047.

27. Holtzapple MT, Davison RR, Ross MK, Aldrett-Lee S, Nagwani M, Lee C, Lee C, Adelson S, Kaar W, Gaskin D (1999) Biomass conversion to mixed alcohol fuels using the MixAlco process. Appl Biochem Biotechnol 79:609-631

28. Plácido J, Zhang Y (2017) Evaluation of esterification and membrane based solvent extraction as methods for the recovery of short 
chain volatile fatty acids from slaughterhouse blood anaerobic mixed fermentation: $1-11$

29. Lopez AM, Hestekin JA (2013) Separation of organic acids from water using ionic liquid assisted electrodialysis. Sep Purif Technol 116:162-169. https://doi.org/10.1016/j.seppur.2013.05.028.

30. Ormerod D, Sledsens B, Vercammen G, Van Gool D, Linsen T, Buekenhoudt A, Bongers B (2013) Demonstration of purification of a pharmaceutical intermediate via organic solvent nanofiltration in the presence of acid. Sep Purif Technol 115:158-162. https://doi. org/10.1016/j.seppur.2013.05.007.

31. Lubsungneon J, Srisuno S, Rodtong S, Boontawan A (2014) Nanofiltration coupled with vapor permeation-assisted esterification as an effective purification step for fermentation-derived succinic acid. J Membr Sci 459:132-142. https://doi.org/10.1016/ j.memsci.2014.02.006. 